\title{
The proper name as starting point for basic reading skills
}

\author{
Anna C. Both-de Vries · Adriana G. Bus
}

Published online: 9 January 2009

(C) The Author(s) 2009. This article is published with open access at Springerlink.com

\begin{abstract}
Does alphabetic-phonetic writing start with the proper name and how does the name affect reading and writing skills? Sixty 4- to 51/2-year-old children from middle SES families with Dutch as their first language wrote their proper name and named letters. For each child we created unique sets of words with and without the child's first letter of the name to test spelling skills and phonemic sensitivity. Name writing correlated with children's knowledge of the first letter of the name and phonemic sensitivity for the sound of the first letter of the name. Hierarchical regression analysis makes plausible that both knowledge of the first letter's name and phonemic sensitivity for this letter explain why name writing results in phonetic spelling with the name letter. Practical implications of the findings are discussed.
\end{abstract}

Keywords Alphabetic-phonetic spelling $\cdot$ Letter knowledge $\cdot$ Early writing development $\cdot$ Name writing · Phonemic sensitivity · Invented spelling

\section{Introduction}

A child's own name is a singularly important benchmark in early literacy development (Ferreiro \& Teberosky, 1982; Welsch, Sullivan, \& Justice 2003). Preschoolers' writing of their own names is identifiable as writing prior to other words and their proper name is among the first words that young children can write conventionally (Levin, Both-de Vries, Aram, \& Bus 2005). Name writing in the

Our thanks to Anne van Duynkerken and Joyce van Thiel for their assistance in the data-collection.

A. C. Both-de Vries $(\bowtie) \cdot$ A. G. Bus

Leiden University, P.O. Box 9555, 2300 RB Leiden, The Netherlands

e-mail: bothanna@fsw.leidenuniv.nl

A. G. Bus

e-mail: bus@fsw.leidenuniv.nl 
preschool stage is also one of the top three predictors of conventional literacy in school age (Badian, 1982; Strickland \& Shanahan, 2004). Identification of the proper name is strongly related to phonological skills and letter-sound knowledge whereas being able to recognize words in the daily environment (e.g., Exit, MacDonalds or CocaCola) is unrelated to phonemic sensitivity or letter-sound knowledge (Blair \& Savage, 2006). Following Ehri's developmental portrayal, children's emerging spelling skills can be described in terms of an increasing ability to parse spoken text and decide what units align with the written form (Ehri \& Wilce, 1985). It is conceivable that name writing marks the start of phonetic writing, due to adult instruction induced by the name. In response to name writing by young children, grown-ups may instruct children in the first letter's name and how this name letter sounds in words by saying things like: "that's /p/ of Peter". Less often grown-ups may instruct children in how random non-name letter sounds by making comments on arbitrary words in print like: "that's /b/ of bear".

If name writing indeed is the starting point for phonetic writing, we might expect phonetic writing to be restricted for a short period to letters from the name. There is no doubt that young children use a variety of letters and not just letters from their own name when they create spelling for dictated words but letters from their own names may be the first ones to be used phonetically at the very start of phonetic writing. However, so far the literature does not provide unanimous support for this hypothesis. For instance, in a group of kindergarten children and first and second graders, Treiman, Kessler, and Bourassa (2001) found that early phonetic spellings of dictated words included letters from the name but other letters as well. In spite of Treiman's findings, it seems sensible to explore the role of the name in early phonetic writing in more depth. In Treiman et al.'s sample (2001), an effect of name letters may not have become manifest because a group that had just started to spell phonetically was mixed up with a more advanced group, thus distorting effects of the name at the very beginning of phonetic writing. In a re-analysis of writings by young children collected in previous studies, we explored the hypothesis that children only use the first letter from the proper name phonetically when they have just started to spell phonetically (Both-de Vries \& Bus, 2008).

When analyzing children's writings, one complicating factor is that young children often select letters from their own name even when the letters do not occur in a word's spelling (Aram \& Levin, 2001; Bloodgood, 1999; Treiman et al., 2001). Bloodgood (1999), for instance, concluded from close examination of writing samples produced by thirty 4- and 5-year-old children that most children devote 30$50 \%$ of their writing to letters from their own name. There is therefore a good chance that, even when letters of the name match sounds in dictated words, the selection of these letters was purely accidental: They chose the letter because its form is familiar and not because they identified any similarity between the pronunciation of their name and the dictated word. We argued that letters of the name are selected by chance when children use name letters equally often in words that include these letter as in words that do not include the letters. If, by contrast, the letters are mainly used when a word's orthography indeed includes name letters, we may assume that the letters are not selected randomly but have been used because children identified the letter sounds in spoken words. A re-analysis of writings by 35 
kindergarten children in the age range of $3 \frac{1}{2}$ to 5 corroborated the theory that phonetic writing starts with the first letter of the proper name (Both-de Vries \& Bus, 2008). All children used conventional symbols in more than half of the dictated words. In so far as children began to write phonetically, as appeared from one or two correct letters in some words, the first letter of the name was often used if words did actually include this letter but rarely in words without the first name letter, meaning that they did not select the first name letter by chance.

By way of contrast, we did not find a similar effect when children mainly produced random letter strings. Children at this less advanced level of writing often used the first letter of their name but then randomly as often as correctly, which means that in this early stage of spelling, letters from the name were chosen by chance and not because children noticed any overlap between their name and the dictated word. Our previous research revealed an effect for the first letter of the name but not for other letters from the name, even though these letters just like the first letter often occurred in children's writing. This suggests that phonetic spelling starts with the first letter of the name. This effect of name writing on spelling new words may be mediated by knowledge of the first letter's name and probably also phonemic sensitivity for this letter. That is, children know how the first name letter sounds in words. Other name letters may be familiar as visual forms but not by name or sound.

\section{This study}

Our findings so far indicate that the first letter of the name, whichever it is, is the sole letter that is written phonetically at the very start of phonetic writing. To explain why the first letter of the name is used phonetically prior to any other letter, we hypothesize that children are familiar with the letter's sound or name and how this letter sounds in words (Foulin, 2005). More than any other letter, the first letter of the child's name may boost instruction thereby promoting letter name knowledge and phonemic sensitivity to the first letter of the name. By saying things like "Look, your letter, /p/ of Peter" grown-ups teach letter names and also that letters refer to sounds in the name and other spoken words (Byrne, 1998; Molfese, Beswick, Molnar, \& Jacobi-Vessels, 2006). Letters thus draw children's attention to the corresponding sounds in words thus making young children aware of the phonemic structure of words (cf. Bus \& Van Ijzendoorn, 1999; Byrne, 1998; Ehri, 1979). Summing up, we expected: (1) that name writing promotes familiarity with the first letter of the name and that children know the first letter of the name better than any other letter, (2) that phonemic sensitivity to the first letter of the name is more developed than phonemic sensitivity to other letters, and (3) that both knowledge of the first letter's name and phonemic sensitivity to this letter benefit the spelling of words that include the first letter.

To test these hypotheses we composed per child two sets of eight words, one with and one without the first letter of the name. We thus prevent that, like in the previous study (Both-de Vries \& Bus, 2008), some name letters do not occur in the dictated words or that very few dictated words include the first letter of the name making scores less reliable. It could happen that the first letter of the name occurred in 1 or 2 dictated words at most, thus making scores more susceptible for chance 
scores. Assuming that letter sounds at the start of words may be easier to identify than letter sounds at the end of words we also controlled where in the word the first letter of the name turned up (Ehri \& Wilce 1987). In half of the words the focal phoneme was the initial sound and in half the last. Furthermore, we designed the study in a way that we could test effects of other characteristics of the first letter that may make it easier to identify this sound in words. Most Dutch consonant names contain the corresponding letter sounds either as initial phoneme, i.e., following the acrophonic principle (CV letter names: B, D, or P) or as final phoneme (VC letter names: F, L, M, N, R, or S). Children may have more to gain from acrophonic CV first letters than from non-acrophonic letters since it is easier to recognize $\mathrm{B}$ in 'Boris' than S in 'Susan'. Furthermore, obstruent consonants such as B, C, and D may be easier to identify in spoken words than less pronounced, sonorant consonants such as L, M, R (Stuart \& Coltheart, 1988). From these aims follows naturally that children were only qualified as participants if their names started with consonants.

To the best of our knowledge this is the first study testing the effect of the ability to write the name on phonemic sensitivity to the first letter of the name. Previous research focused on children's knowledge of the form of name letters (Aram \& Levin, 2001; Bloodgood, 1999; Lavine, 1977; Levin et al., 2005; Treiman, Cohen, Mulqueeny, Kessler, \& Slechtman, 2007; Treiman et al., 2001) and on naming or sounding out the letters of the name (Levin \& Aram, 2004; Treiman \& Broderick, 1998). In line with our previous finding (Both-de Vries \& Bus, 2008), we hypothesize that phonemic sensitivity to the first letter of the name and familiarity with the first letter's name is triggered by name writing, and therefore phonetic writing starts with the first letter of the name.

\section{Method}

\section{Participants}

Participants were 60 Dutch 4- to 51/2-year-olds $(M=57.07, S D=5.12)$, (29 girls and 31 boys). Children were recruited from 11 kindergarten classrooms in eight different schools. As is usual in Dutch kindergartens, formal teaching of reading or writing including instruction of letters was not part of the curriculum. All children were from middle socio-economic status families with Dutch as their first language. All children's first names started with a consonant. Five consonants (B, D, K, P, Y) occurred only once and the rest (C, M, N, T, W, J, L, S) more often (3-11 times). To test effect of characteristics of the first letter we selected participants with $\mathrm{CV}$ and VC first letters. About half $(N=25)$ of the names started with a CV letter (e.g., B, $\mathrm{D}, \mathrm{K})$ and about half $(N=35)$ with a VC letter (e.g., F, R, M). To test effects of the pronunciation of consonants about half $(N=36)$ of the participants' names started with an obstruent consonant (e.g., B, C, D) and half with a less sonorous consonant (e.g., L, M, R). The two classifications were partly confounded. As is known for letters from systems that derive from Latin, Cs in CV-letters (77\%) were more often obstruent than Cs in VC letters (41\%) (Rix, 2008). 


\section{Design}

The study was designed as a within-subjects design where all participants were assessed on each measure. To test spelling skills and phonemic sensitivity, unique sets of stimuli were designed for each child, half with and half without the child's first name letter. The selected words were of equal lengths (three- or four-letter words) and there were good reasons to assume that all words were well known by kindergarten-aged populations (Scharlaekens, Kohnstamm, \& Lejaegere, 1999).

Tests

\section{Dictation}

Apart from their proper name, the children wrote two sets of eight words, one including the first letter of the proper name and one without any letters from the name. In four words the name letter was the first letter and in four words the last letter. For instance, Nico's set with the first letter of his name included eight words: four with $\mathrm{N}$ at the start (Neus [nose], Net [net], Noot [nut], Nagel [nail]), and four words with $\mathrm{N}$ at the end (peN [pen], maN [man], teeN [toe] and zoN [sun]). Although the Dutch orthography is rather shallow, some letters relate to two or more sounds. For instance, the letter $\mathrm{C}$ can be pronounced as $/ \mathrm{s} / \mathrm{or} / \mathrm{k} /$. Composing a set of stimulus words, we selected words in which the sound of the focal letter is similar to the sound in the child's name. Because in Carlo $\mathrm{C}$ is pronounced as $/ \mathrm{k} /$ we dictated eight words starting or ending with $/ \mathrm{k} /$ versus eight words without $/ \mathrm{k} /$.

\section{Phonemic sensitivity}

Children were asked to identify the first or the last sound in 12 spoken words: In six words the target sound was the sound of the first letter of the name; in the other six the target sound was the sound of some other non-name letter. In both sets three words started and three words ended with the focal sound. As control sounds we composed a set of four sounds $(/ \mathrm{b} /, / \mathrm{f} /, / \mathrm{l} /, / \mathrm{w} /)$ that overlapped with the set of sounds related to first name letters. Two sounds related to $\mathrm{CV}$ and two to VC letters, and half was sonorant and half obstruent. Per child we randomly selected from this set of four letters one non name consonant as control letter. The task started with one item to demonstrate the task, and two training items. For each test item the examiner spoke the word out loud while pointing to the corresponding picture. For instance, when testing a child named Sietze, the examiner said 'poes' [cat] while showing a picture of a cat and asking: "Here is a picture of 'poes', which sound do you hear at the end of "poes'?"

\section{Naming letters}

Children were asked to name or sound out letters. When the upper case letter differed from the lower case letter, both forms were presented (e.g., ' $h$ ' and 'H'). Consequently the test included more letters than the alphabet, namely 37 letters. 
Letters were presented on seven separate cards with seven or eight letters on each. The cards were presented one at a time in a randomized order except for the first card that included the first letter of the proper name of the child among seven other letters. Thus the first letter of the name was like all other letters presented as one of eight letters on a card. The experimenter encouraged children to respond to as many letters on a card as possible ("Do you know another one?") but did not highlight any letter in particular (e.g., letters of the name) by pointing or questioning. Both saying the letter name and sounding out were awarded one point. The maximum score was 37.

\section{Procedure}

Assessments were spread over two sessions that each lasted about 20 min. During the sessions the examiner met each child individually in an unused room at school. In both sessions children wrote words and completed items of the phonemic sensitivity task. To prevent order effects contributing to scores on words with and without the name letter, the 16 words in the dictation task were all not dictated in one session but split up in two equal parts. In the first session all children wrote words that included the first letter of their name, and in the second session words without the first letter of the name. The position of the focal letter was counterbalanced: within both sessions half of the children started with four words that included the focal letter at the beginning of the word and half with four words that included the focal letter at the end. For the same reason, the phonemic sensitivity task comprising 12 words was split up in two equal parts with and without the name letter. We administered those two sets in separate sessions counterbalancing the order of the sets with and without the name letter and the position (first or last letter) of the focal letter. In addition to the dictation and phonemic sensitivity task, children wrote their proper name in the first session and they named letters in the second session. So in each session the children completed three short tasks each taking at most 3-4 min. The order of dictation and phonemic sensitivity was counterbalanced; half of the children started with dictation, the other half with phonemic sensitivity, the result being that in the first session half of the children carried out the dictation task immediately after name writing, while the other half did phoneme tasks in between. Name writing in the first session was always done first and naming letters in the second session was always done last. Two trained master students did the testing. In the dictation the examiners asked the child to write a word avoiding indefinite articles: e.g., "write baby."

\section{Coding}

\section{Name writing}

The child's own name was scored on a five-point-scale: correct (e.g., floor for Floor), readable (e.g., DYLA for Dylan), partially correct but not readable (e.g., LeA for Leroy), initial letter correct (e.g., $\mathbf{F}$ for Fenna), and no response or letter-like product (e.g., for Sharin). Most children were unable to produce the name 
letters very well but we accepted deviations that we often saw in young children's writing. For instance, we ignored common deviations from conventional forms like ' $n$ ' written with a projecting line at the top, e.g., $h$ or ' $a$ ' written with a projecting line at the bottom as 0 . For a selection of 18 children, two independent coders agreed substantially on the score of name writing; the intraclass correlation coefficient equaled $r=.82$.

\section{Dictation}

Per child we calculated how often the first letter of the name was used in the set of eight words that included the first letter of the proper name and in the set without this letter, both with a maximum score of 8 . Coding a selection of 30 children, two independent coders agreed substantially on the number of writings that included the first letter of the name; the intraclass correlation coefficient equaled $r=.96$.

\section{Phonemic sensitivity}

Per child we coded how often children succeeded in identifying the first letter of the name in 6 spoken words and how often they succeeded with a non-name stimulus letter. The intraclass correlation coefficient equaled $r=.85$.

\section{Naming letters}

Coding was performed on whether the child correctly named the first letter of the name, the second letter of the name, and how many other letters were named correctly; letter names as well as letter sounds were awarded one point.

\section{Results}

Name writing and letter name knowledge

Of the 60 participants, $39(65 \%)$ wrote their name readably, i.e., they produced at least invented spelling (for instance, Slva instead of Silva) and the rest wrote the name not yet readably $(N=21 ; 35 \%)$. Sixteen children $(27 \%)$ in the latter group wrote the first letter and one or more other letters (for instance, jT instead of Juliet), and $5(8 \%)$ made strings composed of pseudo-letters or pseudo-cursive writing (for instance, $m$ instead of Paul). Does name writing predict children's familiarity with letters of the name? Of the children who wrote the name readably, most children (80\%) were able to name the first letter of their proper name. A small minority $(19 \%)$ of the children who could not write the name readably were able to name or sound out the first letter of the name. See Table 1 for an overview of these results. We can therefore conclude that the correlation between name writing and knowing the first letter of the name was substantial $(\phi=.59, p<.001)$. As is also found by Levin and Aram (2004), children were less familiar with the second name letter. Overall, about one-third (37\%) named this letter correctly. Familiarity with the 
Table 1 Proportion of children that correctly named the first and the second letter of their name as a function of whether they write their name readably or not

\begin{tabular}{|c|c|c|c|}
\hline \multirow[t]{2}{*}{ Name writing } & \multirow[t]{2}{*}{$N$} & \multicolumn{2}{|c|}{ Familiarity with the letters of the name } \\
\hline & & $\begin{array}{l}\text { Knows the first letter } \\
\text { of the name }(\%)\end{array}$ & $\begin{array}{l}\text { Knows the second letter } \\
\text { of the name }(\%)\end{array}$ \\
\hline Not readable & 21 & 19 & 24 \\
\hline Readable & 39 & 80 & 44 \\
\hline
\end{tabular}

name was not an incentive for knowing the second name letter $(\phi=.20$, n.s. $)$. When children wrote their name correctly, they knew more non-name letters than children unable to write their name, 26\% $(S D=31)$ and $14 \% \quad(S D=22)$ respectively, but this difference was not statistically significant.

Name writing and phonemic sensitivity

Does name writing relate to phonemic sensitivity and are children most proficient in identifying the sound of the first letter of their name? A MANOVA revealed that children who wrote their name readably were more successful in identifying sounds in spoken words, $F(1,58)=14.26, p<.001, \eta^{2}=.20$. They identified the first or last sound of a word in about half $(M=5.94, S D=4.03)$ of the test words, whereas children not yet able to write their name identified the sounds in $20 \%$ of the words $(M=2.05, S D=3.38)$. Moreover, the name letter as the first sound of a word $(M=2.80, S D=2.54)$ was easier to identify than the name letter as the last sound of a word $(M=1.78, S D=2.08), F(1,59)=8.05, p<.01, \eta^{2}=.12$ (cf., Yopp, 1988). As is shown in the bottom row of Table 2, children identified the sound of the first letter of their name more often correctly $(M=2.60, S D=2.52)$ than the non-name sound $(M=1.98, S D=2.14) ; F(1,58)=4.09, p<.05, \eta^{2}=.07$. As expected, the contrast between the name and non-name sound was significant when children wrote the name readably $\left(F(1,38)=5.07, p<.05, \eta^{2}=.12\right)$ but not when they were unable to write the name; see Table 2. According to ANOVAs, outcomes were similar for CV versus VC letters and obstruent versus sonorant consonants, indicating that neither letter type nor consonantal strength of the name letter influenced phonemic sensitivity to this letter.

Table 2 Mean scores (and standard deviations) on phonemic sensitivity by the ability to write the proper name

\begin{tabular}{|c|c|c|c|}
\hline \multirow[t]{2}{*}{ Name writing } & \multirow[t]{2}{*}{$N$} & \multicolumn{2}{|c|}{ Identifying sounds in spoken words } \\
\hline & & $\begin{array}{l}\text { The first letter } \\
\text { of the name }\end{array}$ & $\begin{array}{l}\text { Non-name } \\
\text { letters }\end{array}$ \\
\hline Not readable & 21 & $1.19(2.16)$ & $86(1.62)$ \\
\hline Readable & 39 & $3.36(2.39)$ & $2.59(2.16)$ \\
\hline Total & 60 & $2.60(2.52)$ & $1.98(2.14)$ \\
\hline
\end{tabular}


Name writing and invented spelling

Does name writing predict the ability to write words that include the first name letter? As is shown by Table 3, children who are able to write their name selected the first name letter more often to create a spelling $(M=7.82, S D=4.03)$ than children unable to write their name $(M=4.19, S D=5.47) ; F(1,58)=8.59, p<.01$, $\eta^{2}=.13$. When writing the set of 8 words that included the first name letter, children selected this letter more often $(M=4.23, S D=3.14)$ than writing the set without the first letter $(M=2.32, S D=2.76) ; F(1,58)=13.58, p<.001, \eta^{2}=.19$. Furthermore, the name letter as the first letter $(M=2.35, S D=1.76)$ of a word revealed better results than the name letter as a last letter of a word $(M=1.88, S D=1.74), F$ $(1,58)=5.33, p<.03, \eta^{2}=.08$. But, most importantly, if children were able to write their name, they selected the first letter of the name more often for words that actually included this letter than for words without this letter. This contrast was less pronounced in the group as yet unable to write their name. The analyses revealed a statistically significant interaction between name writing and word type; $F$ (1, $58)=4.74, p<.03, \eta^{2}=.08$. When children were able to write their name, they selected the first letter for an average of 5.2 out of eight words with the name letter and for 2.6 out of eight words without this letter; see Table 3. In contrast, the children as yet unable to write the name selected the name letter as often for words that did not include this letter as for words with the letter. In the latter group the first letter occurred on average in two out of eight words, whether words included the first name letter or not; see Table 3. Outcomes were similar when we excluded more advanced children who used other letters than the first letter of the name phonetically $(N=8)$.

Table 3 Mean scores (and standard deviations) on phonetic versus random spelling of the first letter of the name in eight words by the ability to write the proper name

\begin{tabular}{|c|c|c|c|}
\hline \multirow[t]{2}{*}{ Name writing } & \multirow[t]{2}{*}{$N$} & \multicolumn{2}{|l|}{ Using the first letter of the name } \\
\hline & & $\begin{array}{l}\text { Phonetically: in words including } \\
\text { the first letter of the name }\end{array}$ & $\begin{array}{l}\text { Randomly: in words without } \\
\text { the first letter of the name }\end{array}$ \\
\hline Not readable & 21 & $2.43(3.14)$ & $1.76(2.66)$ \\
\hline Readable & 39 & $5.21(2.71)^{\mathrm{a}}$ & $2.62(2.80)^{\mathrm{a}}$ \\
\hline Total & 60 & $4.23(3.14)^{\mathrm{b}}$ & $2.32(2.76)^{\mathrm{b}}$ \\
\hline
\end{tabular}

a The difference was significant, $p<.001$

b The difference was significant, $p<.001$

Furthermore, contrasts between $\mathrm{CV}$ versus VC letters as well as obstruent versus sonorant consonants did not affect correct use of the first letter of the name, meaning that neither letter type nor consonantal strength influenced the spelling.

How does the ability to write the proper name promote phonetic writing with the name letter?

Children may hear overlap in how the name and a dictated word sound and therefore select the first letter of the name to write a new word. Second, it is possible that 
familiarity with the first letter's name explains effects of name writing. Name writing familiarizes children with the first letter and knowing the first letter's name enables children to identify this letter in spoken words and include the letter in the spelling of words. A third possibility is that phonemic sensitivity to the first letter's sound is required as well. In addition to the letter's name children need to be able to identify this letter's sound in spoken words. To choose between these three options we carried out hierarchical multiple regression analysis with as predictors: (1) random writing of the name letter in the set of words that did not include this letter, (2) writing the name readably (five-point scale), (3) familiarity with the first letter of the proper name (dummy-coded), and (4) children's ability to identify the sound of this letter in spoken words (scale), and as dependent measure, their ability to represent the name letter in dictated words that included this letter (maximum score $=8$ ). Predictors were dummy coded (knowing the first letter's name) or grand-mean centered (name writing, random use of the first letter, and identifying the first letter's sound in words). They were entered in the order indicated above.

All variables were moderately correlated as is shown by Table 4. Model 1 in Table 5 shows random use of the first letter to be a significant predictor of phonetic use of the first name letter in spellings, probably because children cannot use this letter phonetically until they are familiar with its form. The second model in Table 5 shows that name writing was a significant predictor of phonetic spelling. The third model in Table 4 supports the hypothesis that knowing the first name letter explains the relationship between name writing and phonetic spelling. In line with this hypothesis, the statistically significant effect of name writing reduced to an insignificant effect $(\beta=.14)$ after familiarity with the name letter was entered. The next step, the addition of phonemic sensitivity to the sound of the first letter, tests whether the identification of the first letter's sound in words explained additional variance. This enables us to determine whether it is not only sufficient for phonetic writing to know the letter by name or sound but whether it also requires identification of the sound in words. Phonemic sensitivity to the first name letter explained additional variance after we controlled for familiarity with the first letter of the name. Familiarity with the first letter of the proper name explained about $9 \%$ of children's spelling ability $(\beta=.28)$, whereas phonemic sensitivity to the name letter explained an additional $21 \%(\beta=.46)$. This result indicates that knowing the first letter's name does not automatically imply that children recognize the

Table 4 Bivariate correlations

\begin{tabular}{lllll}
\hline & $\begin{array}{l}\text { Name } \\
\text { writing }\end{array}$ & $\begin{array}{l}\text { Knowing } \\
\text { name letter }\end{array}$ & $\begin{array}{l}\text { Phonetic sensitivity for } \\
\text { the name letter }\end{array}$ & $\begin{array}{l}\text { Spelling the first letter } \\
\text { of the name phonetically }\end{array}$ \\
\hline $\begin{array}{l}\text { Random writing of the } \\
\text { name letter }\end{array}$ & .14 & .04 & -.20 & $.36^{* * *}$ \\
$\begin{array}{l}\text { Name writing } \\
\text { Knowing name letter }\end{array}$ & $59 * *$ & $.42^{* *}$ & $.45^{* *}$ \\
$\begin{array}{l}\text { Phonetic sensitivity for } \\
\text { the name letter }\end{array}$ & & $.50^{* *}$ & $.54^{* *}$ \\
\hline
\end{tabular}

$* * p<0.01$ (two-tailed) 
Table 5 Prediction of phonetic spelling of the name letter by using random writing of the name letter, knowledge of the first name letter, phonetic sensitivity to the name letter, and name writing

\begin{tabular}{lllll}
\hline Variable & Model 1 & Model 2 & Model 3 & Model 4 \\
\hline $\begin{array}{l}\text { Standardized estimate }(\beta) \\
\quad \text { Random writing }\end{array} \quad .36^{* *}$ & $.30^{* *}$ & $.32^{* *}$ & $.43^{* * *}$ \\
$\quad$ of the name letter & & $.41^{* * *}$ & .14 & .04 \\
$\quad$ Name writing & & $.44^{* * *}$ & $.28^{*}$ \\
$\quad$ Knowing name letter & & & & $.46^{* * *}$ \\
$\quad$ Phonemic sensitivity & & & & \\
$\quad$ to name letter & & $13.14^{* * *}$ & $12.35^{* * *}$ & $17.22^{* * *}$ \\
Model statistics & & 57 & 56 & 55 \\
$F$ (Change) & $586^{* *}$ & .29 & .42 & .56 \\
Error $d f$ & .13 & .27 & .39 & .53 \\
$R^{2}$ & .11 & & & \\
$\Delta R^{2}$ & & & & \\
\hline
\end{tabular}

$* p<.05, * * p<.01, * * * p<.001$

corresponding phoneme in spoken words. The finding that phonemic sensitivity explains variance beyond the variance explained by familiarity with the letter name means that children need to practice how the name letter sounds in spoken words.

\section{Discussion}

Just as in a previous study (Both-de Vries \& Bus, 2008) we found evidence for the hypothesis that the first letter of the name is among the first letters that are written phonetically when children begin to create invented spelling. The study also shows that the ability to write the proper name readably is the starting point for phonetic spelling with the name letter. We wondered why the proper name promotes invented spelling with the name letter. Do children notice the similarity in sound between the start of their name and other words without being aware of the first letter's name or sound? Does familiarity with the first letter of their name enable children to use this letter when they write new words? And is phonemic sensitivity to the first letter a prerequisite to creating word spellings with the first name letter? From the results of this study it is plausible that if children are able to write the proper name they are also able to name the first letter of the proper name. Few children knew the first letter of the name without being able to write their name, meaning that the ability to write the name incentivizes learning the first letter of the name. Furthermore, the first letter of the name is among the first letters of the alphabet known by children (Levin \& Aram, 2004; Treiman \& Broderick, 1998), which suggests that the name, and probably the instruction provoked by name writing, is a main incentive to developing letter knowledge.

Another result is that familiarity with the first letter of the name is important but insufficient to enable phonetic spelling (cf. Levin, 2007). An additional skill, namely identifying the corresponding phoneme in spoken words (phonemic 
sensitivity to the first letter of the name), is an even better predictor for phonetic spelling with the name letter. Both knowing the first letter's name as well as phonemic sensitivity to this letter are required to produce invented spellings with this letter. Another important result of this study is that phonemic sensitivity is promoted by name writing; young children are more successful at identifying the sound of the first name letter in spoken words than at identifying other letters. In the literature, phonemic sensitivity is mostly presented as a bimodal skill that involves all letters, and not as a skill that gradually expands from specific letters like those of the proper name to other letters. Our finding seems more consistent with the hypothesis that phonemic sensitivity is the outcome of instruction related to specific letters. As suggested above, grown-ups may instruct children in how the first name letter sounds in the name by making Rob aware that the sound of his first letter, /r/, can be identified in his name ("that's /r/ of Rob"). We can imagine that phonemic sensitivity does not expand to other letters until children have had practice in how the corresponding phonemes sound in spoken words.

In sum, our data are commensurate with the hypothesis that name writing affects phonetic spelling with the name letter through knowing the first letter's name and phonemic sensitivity to this letter. The alternative theory that children learn to write the first letter of the name and to recognize its sound in spoken words without being able to write the name is not very plausible, though this theory would fit the fourth model in Table 4.

In line with findings reported by Treiman, Tincoff, and Richmond-Welty (1996), it is conceivable that children may spell the first letter of the name more often correctly if this letter is a CV-letter, i.e., the letter name starts with the letter sound like in B and K. VC-letters that end with the letter sound (e.g., S or L) may be more difficult. We expected therefore different outcomes for $\mathrm{VC}$ - and $\mathrm{CV}$-letters to identify in the spoken name. However, our results did not corroborate this hypothesis as there were no effects of letter characteristics; nor did we find evidence for the hypothesis that phonemic sensitivity is less crucial for CV-letters, meaning that phonemic sensitivity is required whatever the qualities of first letters are. In line with findings by Levin (2007), we hypothesize that only the full inclusion of a CV letter name promotes correct spellings but that it rarely happens that CV letter names like K (in Dutch pronounced as $/ \mathrm{ka} /$ ) are fully included in the pronunciation of a Dutch word like $\mathrm{K}$ in kaas [cheese]. In this study the 25 proper names starting with a CV letter included seven different letters; only one (4\%) of the 25 names fully included the letter name, namely $\mathrm{K}$ in Karine. Moreover, four of the seven CV letters were not once fully included in the dictated words; the sounds of other three $\mathrm{CV}$ letters were fully included in at most half of the dictated words.

\section{Future directions and limitations}

Future studies are needed to further explore how familiarity with the orthography of the proper name leads to phonetic spelling. In this study we tested the effects of name production but not the effects of name recognition because we assumed that name production is a better test of knowledge of letters and the name (Levin \& Ehri, 2007). Future studies may include tests of children's ability to recognize their 
written name to test whether recognition is a precursor of alphabetic-phonetic knowledge as well.

On the basis of the available data, we hypothesize that some instruction is indispensable for making a shift towards phonetic spelling (Wise, Sevcik, Morris, Lovett, \& Wolf, 2007; Ziegler \& Goswami, 2005). As grown-ups teach children the first letter's name and how this letter sounds in the name ("look, that's your letter, / t/ of 'Taco'"), they may pave the way to a higher level of understanding of how the written form represents a spoken word. Grown-ups thus focus children's attention on letter units and how they sound in spoken words, thereby promoting writing that goes beyond mere imitation of the written form. In other words, we may assume that grown-ups provide children with fairly substantial amounts of direct instruction about letters as symbols when they speak about children's own or other people's letters and how they sound in words (Levin \& Aram, 2004; Welsch et al., 2003).

Even though available evidence suggests that early writing develops likewise for various countries (Levin \& Bus, 2003), we wonder whether the current results, found in a Dutch sample, can be replicated in countries where teaching of reading starts earlier and kindergarten children are taught the letters from an earlier age. As teaching the alphabet or letter names is not part of the kindergarten curriculum, learning may depend on informal print experience like name writing and grownups' responses to such products of writing. It is also conceivable that practice of letter names is a waste of time until children develop some rudimentary understanding of the basic concepts of phonetic writing.

One limitation of the present study may have been that the stimulus material differed per child and that consequently the outcomes varied. For instance, the nonname letter selected to assess phonemic sensitivity only met the criterion that it was not a letter from the name. However, we did not find evidence that features of nonname letters may have distorted the results. For instance, scores on the phonemic sensitivity task with the non- name letter were similar for CV and VC letters and for sonorant and obstruent sounds.

It may have been a weakness of the design that the dictation of words that included the first letter of the name and name writing occurred in the same session, which may have stimulated children to include letters of their name in the dictated words. Contra-indicative for this hypothesis may be that half of the children did three other tasks between name writing and the dictation but nonetheless used the first letter of the name as often in the word dictation. However in future work it is important to order all tasks in such a way that order effects cannot interfere with interpretation.

\section{Implications}

The finding that a rudimentary activity like name writing is an incentive to understanding how letter symbols represent meaning does not mean that learning basic skills happens without instruction (Wise et al., 2007; Ziegler \& Goswami, 2005). Children need a support system of prompts, hints, and feedback for writing the proper name (Gillanders \& Jimenez, 2004) especially when they show less interest in name writing (Bus \& Out, 2008). And, more importantly, they probably 
need social interactions in which the child and the adult are jointly attending letters and words (Tomasello, 1999). When children are able to produce some invented spelling but lack basic skills for a more complete representation of what they intend to write, they do not actively look for ways to expand their phonetic-alphabetic knowledge (Tolchinsky, 2003); they then mostly revert to simpler strategies like random letter strings or pseudo-cursive scribble (Bus et al., 2001).

Open Access This article is distributed under the terms of the Creative Commons Attribution Noncommercial License which permits any noncommercial use, distribution, and reproduction in any medium, provided the original author(s) and source are credited.

\section{References}

Aram, D., \& Levin, I. (2001). Mother-child joint writing in low SES: Sociocultural factors, maternal mediation, and emergent literacy. Cognitive Development, 16, 831-852.

Badian, N. A. (1982). The prediction of good and poor reading before kindergarten entry: A 4-year follow-up. The Journal of Special Education, 16, 309-318.

Blair, R., \& Savage, R. (2006). Name writing but not environmental print recognition is related to lettersound knowledge and phonological awareness in pre-readers. Reading and Writing, 19, 991-1016.

Bloodgood, J. W. (1999). What's in a name? Children's name writing and literacy acquisition. Reading Research Quarterly, 34, 342-367.

Both-de Vries, A. C., \& Bus, A. G. (2008). Name writing: A first step to phonetic writing? Does the name have a special role in understanding the symbolic function of writing? Literacy Teaching and Learning, 12, 37-55.

Bus, A. G., Both-de Vries, A. C., de Jong, M. T., Sulzby, E., de Jong, W., \& de Jong, E. (2001). Conceptualizations underlying emergent readers' story writing. Anna Arbor, MI: Ciera Report \#2.015.

Bus, A. G., \& Out, D. (2008). Unraveling genetic and environmental components of early literacy; a twin study. Reading and Writing (in press). doi:10.1007/s11145-008-9115-0.

Bus, A. G., \& Van Ijzendoorn, M. H. (1999). Phonological awareness and early reading: A meta-analysis of experimental training studies. Journal of Educational Psychology, 91, 403-414.

Byrne, B. (1998). The foundation of literacy. The child's acquisition of the alphabetic principle. East Sussex, UK: Psychology Press Ltd.

Ehri, L. C. (1979). Linguistic insight: Threshold of reading acquisition. In G. Waller \& G. Mackinnon (Eds.), Reading research: Advances in theory and practice (Vol. 1). New York: Academic Press.

Ehri, L. C., \& Wilce, L. S. (1985). Movement into reading: Is the first stage of printed word learning visual or phonetic? Reading Research Quarterly, 20, 163-179.

Ehri, L. C., \& Wilce, L. S. (1987). Does learning to spell help beginners to read words? Reading Research Quarterly, 22, 47-65.

Ferreiro, E., \& Teberosky, A. (1982). Literacy before schooling. Portsmouth, NH: Heinemann.

Foulin, J. N. (2005). Why is letter-name knowledge such a good predictor of learning to read? Reading and Writing, 18, 129-155.

Gillanders, C., \& Jimenez, R. T. (2004). Reaching for success: A close-up of Mexican immigrant parents in the USA who foster literacy success for their kindergarten children. Journal of Early Childhood Literacy, 4, 243-269.

Lavine, L. (1977). Differentiation of letterlike forms in prereading children. Developmental Psychology, 23, 89-94.

Levin, I. (2007). The role of Hebrew letter names in early literacy: The case of multiphonemic acrophonic names. Journal of Experimental Child Psychology, 98, 193-216.

Levin, I., \& Aram, D. (2004). Children's names contribute to early literacy: A linguistic and social perspective. In D. Ravid \& H. Bat-Zeev Shyldkrot (Eds.), Perspectives on language and language development. Dordrecht: Kluwer.

Levin, I., Both-de Vries, A. C., Aram, D., \& Bus, A. G. (2005). Writing starts with own name writing: From scribbling to conventional spelling in Israeli and Dutch children. Applied Psycholinguistics, 26, 463-477. 
Levin, I., \& Bus, A. G. (2003). How is emergent writing based on drawing? Analyses of children's products and their sorting by children and mothers. Developmental Psychology, 39, 891-905.

Levin, I., \& Ehri, L. C. (2007). Young children's ability to read and spell their own and classmates' names: The role of letter knowledge. Unpublished Manuscript.

Molfese, V. J., Beswick, J., Molnar, A., \& Jacobi-Vessels, J. (2006). Alphabetic skills in preschool: A preliminary study of letter naming and letter writing. Developmental Neuropsychology, 29, 5-19.

Rix, H. (2008). Etruscan. In R. D. Woodard (Ed.), The ancient languages of Europe (pp. 141-164). Cambridge: Cambridge University Press.

Scharlaekens, A., Kohnstamm, G. A., \& Lejaegere, M. (1999). Streeflijst woordenschat, voor 6-jarigen [Target vocabulary list for 6-year-olds]. Lisse: Swets \& Zeitlinger.

Strickland, D. S., \& Shanahan, T. (2004). Laying the groundwork for literacy-Preliminary findings from the National Early Literacy Panel. Educational Leadership, 6, 74-77.

Stuart, M., \& Coltheart, M. (1988). Does reading develop in a sequence of stages? Cognition, 30, 139-181.

Tolchinsky, L. (2003). The cradle of culture and what children know about writing and numbers before being taught. London: Lawrence \& Erlbaum.

Tomasello, M. (1999). The cultural origins of human cognition. Cambridge: Harvard.

Treiman, R., \& Broderick, V. (1998). What's in a name? Children's knowledge about the letters in their own names. Journal of Experimental Child Psychology, 70, 97-116.

Treiman, R., Cohen, J., Mulqueeny, K., Kessler, B., \& Slechtman, S. (2007). Young children's knowledge about printed names. Child Development, 78, 1458-1471.

Treiman, R., Kessler, B., \& Bourassa, D. (2001). Children's own names influence their spelling. Applied Psycholinguistics, 22, 555-570.

Treiman, R., Tincoff, R., \& Richmond-Welty, E. D. (1996). Letter names help children to connect print and speech. Developmental Psychology, 32(3), 505-514.

Welsch, J. G., Sullivan, A., \& Justice, L. M. (2003). That's my letter!: What preschoolers' name writing representations tell us about emergent literacy knowledge. Journal of Literacy Research, 2, 757776.

Wise, J. C., Sevcik, R. A., Morris, R. D., Lovett, M. W., \& Wolf, M. (2007). The growth of phonological awareness by children with reading disabilities: A result of semantic knowledge or knowledge of grapheme-phoneme correspondences? Scientific Studies of Reading, 11(2), 151-164.

Yopp, H. K. (1988). The validity and reliability of phonemic awareness tests. Reading Research Quarterly, 23, 159-177.

Ziegler, J. C., \& Goswami, U. (2005). Reading acquisition, developmental dyslexia, and skilled reading across languages: A psycholinguistic grain size theory. Psychological Bulletin, 131, 3-29. 